\title{
Andamiaje de la autorregulación académica a través del correo electrónico en un programa de formación docente de modalidad mixta
}

\section{Scaffolding of academic self-regulation via e-mail in a teacher education program blended learning}

\author{
Marcos Antonio Requena Arellano \\ Universidad Católica Andrés Bello. Venezuela \\ mrequena@ucab.edu.ve
}

\begin{abstract}
Resumen
La investigación tuvo como objetivo analizar el andamiaje dado a la autorregulación académica mediante el correo electrónico en el primer semestre de un programa universitario de modalidad mixta. Se sustentó en un modelo cíclico del aprendizaje autorregulado, tres tipologías de andamiaje en entorno digital y aportes hechos respecto a la moderación de comunidades de aprendizaje. Se realizó mediante aplicación de técnicas propias del método comparativo continuo de la teoría fundamentada. Los resultados destacan que: a) el andamiaje dado por los docentes muestra grandes diferencias de un docente a otro, tanto en el volumen de andamios ofrecidos como en sus tipos; b) los andamios dados son en su totalidad indirectos y en su mayoría fijos; c) los procesos que prevalecientemente se apoyan son los de la etapa de previsión y la etapa de desempeño, dejando con un andamiaje marginal los de la etapa de reflexión. Se concluye que en el programa y semestre objetos de atención la herramienta del correo electrónico es empleada en el andamiaje de la autorregulación académica en una medida, modalidad y fines susceptibles de ser mejorados. Resulta recomendable incrementar el andamiaje adaptativo, así como incluir el andamiaje a los procesos de la fase reflexiva.
\end{abstract}

\section{Palabras clave}

Educación digital; autorregulación académica; andamiaje; Blackboard Learn; correo electrónico

\begin{abstract}
The research aimed to analyze the scaffolding given to academic self-regulation by e-mail in the first semester of a college program mixed mode. It was based on a cyclical model of self-regulated learning, three types of scaffolding at digital environment and contributions made regarding moderation of learning communities. It was conducted by applying techniques of the continuous comparative method of grounded theory. The results include: a) the scaffolding given by teachers shows large differences from one teacher to another, both the volume of scaffolding offered and their types; b) scaffolds given are indirect in its whole and mostly fixed; c) the processes supported are prevalently of the prediction stage and performing stage, leaving a marginal scaffolding to the reflection stage. It is concluded that in the program and semester objects of attention email tool is used in the scaffolding of academic self-regulation to an extent, form and purpose that can be improved. Result recommended increasing the adaptive scaffolding and include scaffolding of the processes of reflective phase.
\end{abstract}

\section{Key words}

Digital education, academic self-regulation, scaffolding, Blackboard Learn, email. 


\section{Introducción}

Actualmente se registra una acelerada migración de las ofertas educativas, de la tradicional modalidad presencial a modalidades permitidas por el uso de las tecnologías de la información y la comunicación (TIC). En esta migración, los procesos de enseñanza y aprendizaje se independizan de las dimensiones espacio-temporales: a un entorno digital se le accede en cualquier momento desde cualquier parte, con los únicos requerimientos de un dispositivo conectado a Internet; en él se construyen objetos y realidades inmateriales y hay cabida simultánea para un indeterminado número de usuarios (Hernández, 2008). Estas condiciones exigen del estudiante la implementación de estrategias dirigidas a regular su aprendizaje, que le permitan manejar eficazmente sus procesos motivacionales y cognitivos, gestionar su tiempo y controlar los elementos del entorno (Azevedo, Jeffrey, Greene y Moos, 2007). En correspondencia con esta exigencia, Devolder, Van Braak y Tondeur (2012) y Benz (2010) sostienen que se espera que los agentes educacionales (principalmente de los docentes) brinden a los estudiantes andamios para la aplicación de estas estrategias de autorregulación académica.

La Universidad Católica Andrés Bello (UCAB) oferta un programa de modalidad mixta, el Programa Especial de Licenciatura en Educación (PRESLIED), dirigido a la formación docente de profesionales de otras áreas que se desempeñan en el campo educativo. El programa, de cuatro semestres, se desarrolla fundamentalmente mediante un aula virtual diseñada en plataforma Blackboard Learn.

El presente artículo reporta parte de una investigación dirigida a analizar el andamiaje para la autorregulación del aprendizaje, ofrecido mediante Blackboard Learn a los estudiantes del primer semestre del referido programa, durante el período académico: octubre 2014 - febrero 2015. La parte que aquí se focaliza está constituida por la entrega de andamios mediante el correo electrónico, una de las herramientas comunicacionales del aula virtual.

Los objetivos de reportar mediante este artículo la referida indagación sobre la provisión de andamios a la autorregulación mediante el correo electrónico es ofrecer tres tipos de aportes a la comunidad académica y científica interesada en el tema: a) teóricos, representados por las categorías de andamios que se dan a conocer; b) metodológicos, consistentes en los modos mediante los cuales se recolectaron y analizaron los datos; c) didácticos, implicados en los tipos de andamios que se indican y que pueden ser usados como estrategias por cualquier tutor que desee dar apoyo mediante el correo electrónico a la autorregulación académica de sus estudiantes. Estos tres tipos de aportes están dados por el hecho de que la mayoría de los reportes de investigación hallados mediante indagación en repositorios, relativos a análisis de intercambios de correo electrónico entre docentes y estudiantes, tratan tópicos distintos al andamiaje.

Los estudiantes del PRESLIED reciben correos electrónicos de los profesores de las materias, de la Coordinación del PRESLIED -adscrita a la Escuela de Educación- y del Centro de Estudios en Línea (CEL) -responsable de la gestión del aula virtual-. No obstante, por razones de tiempo y de espacio, la ponencia presenta sólo los resultados del análisis de los correos enviados por los profesores.

Las materias del Primer Semestre son cuatro: Introducción al Estudio del Hombre (IEH), Práctica Profesional I (PPI), Psicología General y del Desarrollo (PGD) y Sociología de la Educación (SE). Durante el período objeto de análisis no se registran correos electrónicos enviados por el profesor de esta última materia. Al respecto, el

Andamiaje a la autorregulación académica a través del correo electrónico en un programa de formación docente de modalidad mista. Marcos Antonio Requena Arellano

Página 2 de 25 
profesor informa al investigador haber eliminado los dos o tres correos que enviara a los estudiantes durante el semestre.

\section{Marcos referencial}

Como explican Efklides (2009) y Pintrich (2004), el término aprendizaje autorregulado es un constructo que hace referencia a un tipo de aprendizaje en el que el estudiante activa y pone en uso de manera consciente y deliberada una compleja gama de procesos cognitivos, metacognitivos y motivacionales al servicio del logro de objetivos previamente establecidos.

Zimmerman (1989, 2008, 2013), basado en un enfoque socio-cognitivo del aprendizaje, plantea un modelo cíclico de la autorregulación del aprendizaje (Figura 1).

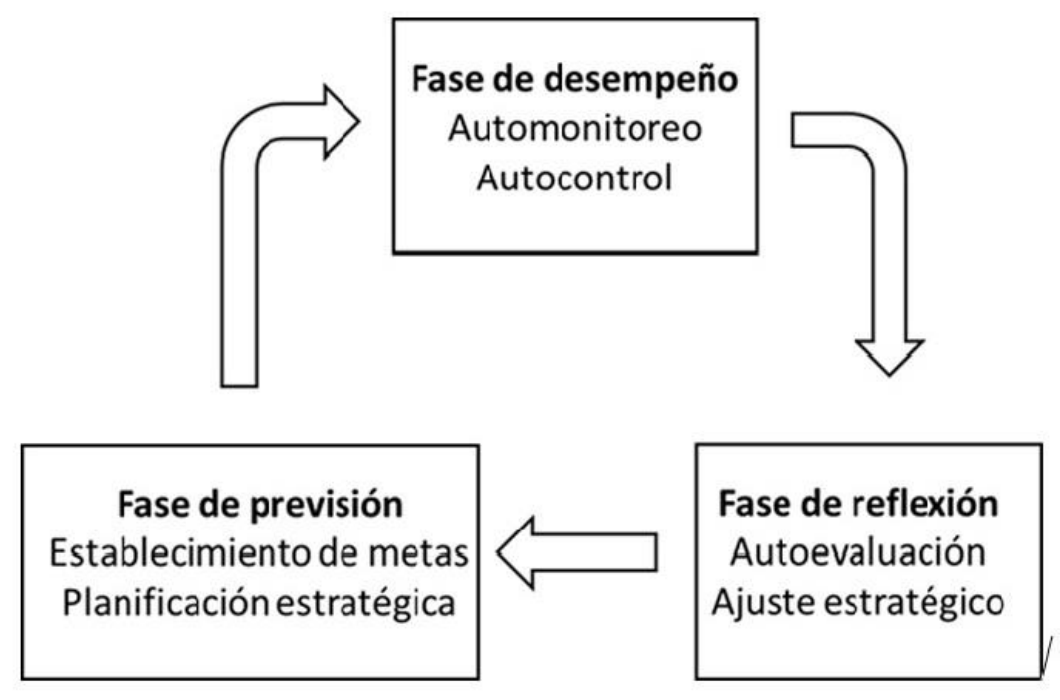

Figura 1. Fases y subprocesos de la autorregulación. Propuesta de Zimmerman (1989). Fuente: Zimmerman (1989).

Como señala la Figura 1, el modelo establece que la autorregulación del aprendizaje tiene lugar en un ciclo de tres fases metacognitivas:

a) Previsión, fase previa a la realización de la actividad de aprendizaje. En la misma, se aplican estrategias de establecimiento de metas y planificación. El establecimiento de metas consiste en la fijación de objetivos para la actividad que se tiene planteada, así como el momento en que dicho objetivo debe estar logrado. Para ello, el estudiante considera la naturaleza de la tarea, las condiciones y su conocimiento previo sobre el contenido involucrado. En la planificación, determina las estrategias que aplicará para lograr las metas planteadas.

b) Desempeño, fase coincidente con la ejecución de la actividad de aprendizaje. Se aplican estrategias de automonitoreo y regulación de procesos. El automonitoreo consiste en la atención de los propios procesos y resultados, comparándose lo planificado con lo que se está ejecutando, así como las metas fijadas con los logros que se están obteniendo. Con base en esta comparación, el estudiante regula los procesos: los mantiene como los está ejecutando o les hace modificaciones.

c) Reflexión, fase posterior a la realización de la actividad de aprendizaje. Se ejecutan estrategias de autoevaluación y ajuste de procesos. Con la autoevaluación, el estudiante compara los logros obtenidos con las metas previamente establecidas, así como las estrategias planificadas con las ejecutadas; hace juicios sobre la eficacia de

Andamiaje a la autorregulación académica a través del correo electrónico en un programa de formación docente de modalidad mista. Marcos Antonio Requena Arellano

Página 3 de 25 
éstas y valora su propia actuación. Con base en este proceso reflexivo, hace consideraciones para una futura oportunidad en la que deba enfrentar una actividad de aprendizaje similar, precisando ajustes a las estrategias aplicadas previamente.

Además de estas estrategias metacognitivas, a lo largo de las tres fases el aprendiz debe aplicar estrategias orientadas al control de su motivación y sus emociones, por lo que el modelo -en coincidencia con los de Pintrich (2004) y Winne (2005)- contempla una variedad de factores y procesos intervinientes en la dinámica motivacional del estudiante, que pueden ser promovidos por el profesor en contexto comunicacional: la afectividad y el clima social (Gárrison y Anderson, 2005; Sánchez-Upegui, 2009), la autoeficacia (Cho, 2012), la orientación al objetivo y la valoración de la tarea (Efklides, 2009; Pintrich, 2004).

De acuerdo con el mismo enfoque socio-cognitivo, la autorregulación del aprendizaje es susceptible de recibir andamiaje. En relación con este tipo de intervención pedagógica, Azevedo, Cromley, Moos, Grenne y Winters (2011) sostienen que integra cuatro elementos: a) la comprensión compartida del objetivo de aprendizaje entre docente y estudiante; b) el requerimiento de una evaluación continua de procesos y logros del estudiante; c) la calibración del apoyo docente de acuerdo con los progresivos logros del estudiante; d) la consecuente individualización del apoyo. Con base en estos elementos, se comprende que el andamiaje para el aprendizaje autorregulado contempla dos acciones paralelas:

a) Andamiaje para ayudar al estudiante a autorregularse.

b) Andamiaje para soportar en el estudiante el desarrollo de procesos autorregulatorios.

La literatura sobre andamiaje del aprendizaje autorregulado en entornos digitales presenta una variedad de clasificaciones de los andamios. De acuerdo con el criterio que se considere, éstos pueden recibir distintas clasificaciones:

a) De acuerdo con la adaptabilidad, puede ser fijo o adaptativo (Azevedo, Cromley, Moos, Grenne y Winters, 2011; Cho, 2012): el fijo se ofrece independientemente de las diferencias individuales de los estudiantes, por lo que se da a todo el grupo, mientras el adaptativo depende de las necesidades individuales de los estudiantes.

b) Según el estilo, puede ser directo o indirecto (Benz, 2010): el primero ayuda al estudiante a ejecutar una estrategia de autorregulación en el que muestra tener dificultades, mientras el segundo solamente induce en el estudiante una toma de decisión respecto de qué estrategia de autorregulación aplicar.

c) De acuerdo con el objeto sobre el que recae el andamio, éste puede considerarse motivacional, cognitivo o metacognitivo (Boekaerts, 1999), así como andamio a la previsión, al desempeño o a la reflexión, las tres fases del aprendizaje autorregulado descritas por Zimmerman (1989, 1998, 2013).

En relación con el andamiaje que puede ofrecerse al aprendizaje autorregulado mediante el correo electrónico, desde la irrupción de las TIC en la educación, una variedad de autores (por ejemplo, Hodges \& Kim, 2010; Inglis, 1998; Kim, 2008; Lee, 2001; Monforte, 2003; Pastor Cesteros, 1999; Puerta y Sánchez, 2010; Spence, 2002) sostienen la potencialidad del correo electrónico para promover o apoyar en los estudiantes procesos cognitivos, metacognitivos o motivacionales.

Inglis (1998), al reportar los resultados de una investigación contextualizada en un curso de arte a nivel superior, hace dos aseveraciones: a) que en la educación a distancia, el correo electrónico es particularmente efectivo para ofrecer de manera continua

Andamiaje a la autorregulación académica a través del correo electrónico en un programa de formación docente de modalidad mista. Marcos Antonio Requena Arellano

Página 4 de 25 
retroalimentación a los estudiantes sobre sus asignaciones; b) que tal retroalimentación puede eficazmente realizarse no solo en formato de texto sino también audiovisual, mediante cortos videos. Una condición importante para que el video sea útil como provisor de retroalimentación es que en poco tiempo (aproximadamente dos minutos) ofrezca información que pueda ser aprovechada para la mejora de los procesos que se busca retroalimentar.

Pastor Cesteros (1999) señala cuatro rasgos del correo electrónico, que lo hacen valioso en el campo educativo: a) representa un intercambio auténtico: se tiene seguridad de que lo que se escribe va a ser leído por aquél al que se envía; b) puede comunicar tanto ideas como emociones, con estilos intermedios entre la comunicación oral y la escritura formal; c) en relación con otros modos de expresión escrita, tiende a la inmediatez: la prontitud con la que se forma la secuencia comunicacional; d) por lo anterior, potencia la motivación de los participantes en la comunicación y favorece su interactividad.

Lee (2001), con explícito fundamento en la teoría triárquica de inteligencia de Sternberg y la teoría de la Zona de Desarrollo Próximo de Vygotsky, sostiene que el correo electrónico puede emplearse para promover, en el marco de actividades de aprendizaje colaborativo, el desarrollo de habilidades de pensamiento autorregulado. Sostiene que para ello, es importante que: a) el contexto de la comunicación sea un contexto personalmente significativo para los estudiantes; b) se promuevan en éstos habilidades tanto personales, como intelectuales y sociales; c) se brinde a los estudiante con riesgo académico oportunidades de comunicarse con compañeros y de experimentar el éxito; d) se evalúe con frecuencia los procesos de pensamiento implicados en las preguntas y respuestas dadas por los estudiantes durante la comunicación.

Spence (2002) dedica su trabajo a analizar los aspectos en el uso del correo electrónico que, por sus implicaciones éticas, deben ser considerados cuando la herramienta es empleada en contexto educativo. En tal sentido, de su análisis consideramos en este trabajo tres rasgos del correo electrónico:

a) La tendencia de los interlocutores a transmitir ideas que no manifestarían personalmente y a escribir sin considerar las reglas gramaticales. La primera tendencia genera la necesidad de que el docente respete la privacidad de los estudiantes con quienes mantiene comunicación a través de dicho medio; la segunda, la conveniencia de que tolere en los estudiantes la desconsideración de la gramática por tal medio de comunicación.

b) Su potencial contribución a la cohesión social, al facilitar la expresión de personas a las que se les dificulta su manifestación cara a cara (este rasgo también es resaltado por Lee, 2001 y Monforte, 2003). Esta potencialidad permite que el docente aproveche el correo electrónico para fortalecer la cohesión del grupo estudiantil.

c) Las posibilidades de la difusión inapropiada de información que previamente se ha manejado en él, pudiendo generar prejuicios a los iniciales emisores de la información. Considerar esta posibilidad lleva al docente a promover en los estudiantes la importancia del respeto a la intimidad con quienes mantienen comunicación vía correo electrónico.

Tomar en consideración estos tres rasgos del correo electrónico incrementa su potencialidad para emplearse en función de la provisión de andamios a la autorregulación del aprendizaje.

Monforte (2003) señala la importancia de que el docente envíe a los estudiantes, por lo menos una vez a la semana, mensajes cuyo tipo dependa del progreso de éstos en sus

Andamiaje a la autorregulación académica a través del correo electrónico en un programa de formación docente de modalidad mista. Marcos Antonio Requena Arellano

Página 5 de 25 
estudios. En tal sentido, señala cuatro tipos de mensajes que, alternativamente, puede enviar el docente a los estudiantes y que pueden ser considerados andamios para la autorregulación del aprendizaje:

a) Mensajes administrativos, como recordatorios de fechas clave y convocatorias a jornadas presenciales.

b) Mensajes académicos, como actualizaciones del temario o fuentes.

c) Mensajes generales de seguimiento, como recordatorios de la unidad o sesión en la que se debe estar, recordatorios de actividades y asignaciones que se debieron haber entregado.

d) Mensajes personalizados, como felicitaciones por buen desempeño, preguntas por retrasos en actividades o asignaciones y ofrecimientos de ayuda para actualizarse en éstas.

Kim (2008) se interesa explícitamente en las estrategias que, a través del correo electrónico, pueden dar soporte a un aprendizaje motivador, eficaz y eficiente. Señala que para dar este soporte se debe tomar en cuenta aspectos cognitivos y no cognitivos del aprendizaje.

Con base en una amplia revisión de reportes de investigación, este autor sostiene que el correo electrónico:

a) Es una excelente herramienta para ofrecer soporte continuo a los estudiantes (lo mismo proponen Lee, 2001 y Spence, 2002)

b) Puede fomentar la cercanía entre estudiantes y docente debido al soporte de la seguridad psicológica (sostenido igualmente por Hodges y Kim, 2010 y Spence, 2002)

c) Puede fomentar las habilidades interpersonales, al promoverse en los estudiantes la interacción positiva con los demás (idea compartida con Lee, 2001)

d) Puede ser empleado para dar soporte a la motivación de los estudiantes, promoviendo la autoeficacia, la autoestima y el cambio de valores personales (propuesta compartida con Hodges y Kim, 2010 y Lee, 2001)

e) Puede ser empleado para el pensamiento reflexivo y crítico (igual proponen Hodges y Kim, 2010);

f) Tiene como mensajes más relevantes los dedicados al fomento del trabajo colaborativo y el análisis de rendimiento individual (aseveración compartida con Puerta y Sánchez, 2010).

El mismo autor -Kim (2008)-, con base en la experiencia compartida y acreditada, propone un marco conceptual cíclico para la provisión de apoyo al aprendizaje eficaz, eficiente y atractivo mediante el correo electrónico. Dicho marco está compuesto por tres momentos/procesos: a) diagnóstico de las necesidades de los estudiantes; b) provisión de apoyos vía correo electrónico; c) manejo, por parte del estudiante, de procesos cognitivos y no cognitivos.

Según explica Kim (2008) al describir las dos primeras fases del ciclo -que son las que corresponden con la actuación del docente- el diagnóstico se realiza globalmente a todo el grupo de estudiantes o individualmente a cada estudiante, e incluye aspectos como conocimientos, creencias, habilidades y actitudes. 
Por su parte, la segunda fase -la provisión de apoyos mediante correos- incluye cuatro acciones: a) mejorar la atención en los aspectos sustantivos del contenido; b) incrementar la relevancia del contenido, enfatizando el uso que el estudiante puede darle al contenido; c) fomentar la confianza del estudiante, buscando convencerlos de que lograrán los objetivos de aprendizaje si aplican las estrategias sugeridas; d) contribuir con la satisfacción estudiantil, mostrando implicaciones del logro de los objetivos.

Estas cuatro acciones de la fase de provisión de apoyos del marco conceptual cíclico de Kim (2008) pueden ser válidamente interpretadas como andamios al aprendizaje autorregulado, dada la coincidencia conceptual entre los conceptos de apoyo y aprendizaje eficaz, eficiente y motivador, por una parte y respectivamente, con los conceptos de andamio y aprendizaje autorregulado.

Por su parte, Puerta y Sánchez (2010), en una investigación empírica, encuentran seis tipos de mensajes de correo enviados por docentes, con intención comunicativa y favorecedores del acto educativo: a) saludo, bienvenida y despedida con cortesía; b) información de algún modo pertinente al curso; c) orientación sobre actividades; d) exhortación; e) valoración de logros y f) cierre de actividad. Por su relación con los componentes y procesos de la autorregulación, estos mensajes pueden ser igualmente interpretados como andamios de la autorregulación académica

Hodges y Kim (2010) realizan un estudio sobre el fomento de la autorregulación y la autoeficacia mediante el correo electrónico. Sustentan su estudio en los planteamientos de Zimmerman (1989) sobre la autorregulación y en los de Bandura (1977) sobre la autoeficacia.

Los mensajes de correo electrónico ofrecidos a los estudiantes buscaron favorecer los procesos metacognitivos asociados con las dos primeras fases del aprendizaje autorregulado (previsión y desempeño) y con la autoeficacia. El Cuadro 1 presenta los mensajes de correo electrónico utilizados por los autores a lo largo de once (11) semanas para darle apoyo a los procesos referidos. Tales mensajes fueron precedidos de un breve saludo: impersonal, como "Hola" o personalizado, como "Hola, fulano": el primer tipo de saludo inició los mensajes enviados a un grupo experimental; el segundo, al otro grupo experimental.

Cuadro 1. Contenido de mensajes de correo electrónico propuestos por Hodges y Kim (2010) para fomentar la autorregulación de los estudiantes.

\begin{tabular}{|c|c|}
\hline $\begin{array}{c}\text { Estrategia de } \\
\text { autorregulación objeto } \\
\text { de apoyo }\end{array}$ & Mensajes de correo electrónico \\
\hline Planificación & $\begin{array}{l}\text { 1. Asegúrate de asignar suficiente tiempo para tu } \\
\text { curso de Matemáticas esta semana. } \\
\text { 2. Esta semana, no te olvides reservar un tiempo para } \\
\text { estudiar Matemática. }\end{array}$ \\
\hline $\begin{array}{l}\text { Planificación y } \\
\text { establecimiento de } \\
\text { objetivos }\end{array}$ & $\begin{array}{l}\text { 1. El horario con los plazos para las pruebas de } \\
\text { Matemáticas está disponible en la página Web del } \\
\text { curso. } \\
\text { 2. Es una buena estrategia de estudio que te } \\
\text { establezcas objetivos de aprendizaje en } \\
\text { Matemáticas. }\end{array}$ \\
\hline & $\begin{array}{l}\text { 3. Es una buena estrategia de estudio que te } \\
\text { establezcas objetivos de desempeño en }\end{array}$ \\
\hline
\end{tabular}

Andamiaje a la autorregulación académica a través del correo electrónico en un programa de formación docente de modalidad mista. Marcos Antonio Requena Arellano 


\begin{tabular}{cc}
\hline Estrategia de & Mensajes de correo electrónico \\
autorregulación objeto \\
de apoyo
\end{tabular}

\begin{abstract}
Automonitoreo y autorrefuerzo
\end{abstract}

Automonitoreo y autoinstrucción
Matemáticas.

1. Puedes hacer un seguimiento de tu progreso en Matemáticas consultando el libro de calificaciones en la página Web del curso.

2. No olvides hacer un seguimiento de tu progreso en Matemáticas consultando el libro de calificaciones en la página Web del curso.

1. Puedes revisar tu preparación para los exámenes de Matemáticas haciendo una práctica con el programa de pruebas cortas.

2. En Matemáticas, es una buena estrategia que, antes de estudiarlos, eches una ojeada global a los materiales de las lecciones.

\section{Metodología}

La investigación se realiza mediante la aplicación de un análisis cualitativo de contenido (Cáceres, 2003). En tal sentido, se realizan los siguientes pasos: a) selección del mensaje mediante correo electrónico del profesor de cada materia como objeto de análisis, y en el marco de los procesos mediacionales del aprendizaje; b) determinación de frase como unidad de análisis; c) determinación, con base en la literatura, de los códigos para la designación y categorización de los andamios; d) establecimiento de la reglas de análisis: se codifica una frase si contiene un mensaje de algún modo asociado con la autorregulación del estudiante; se agrupa bajo el mismo código las frases con el mismo aporte a la autorregulación estudiantil; y se categoriza cada andamio de acuerdo con tres criterios: adaptabilidad, proceso que apoya y fase a la que pertenece este proceso; e) realización del análisis.

En la recolección de datos se recopilan y analizan los correos electrónicos enviados por tres de los cuatro profesores del primer semestre del programa, durante el período académico octubre 2014 - febrero 2105, bien a través del aula virtual (en plataforma Blackboard Learn 9.1), bien -en algunos casos- por cuenta personal del docente. El acceso a los correos electrónicos se posibilitó gracias al permiso concedido por los profesores y por el Centro de Estudios en Línea de la universidad (órgano gestor del aula virtual) para que el investigador tuviera inscrito en las materias como estudiantes. Con dicho estatus, se logró que el investigador recibiera todos los mensajes de correos enviados al grupo de estudiantes. Por otra parte, los profesores accedieron a enviar al investigador copia de todos los correos que enviaron de manera individual a los estudiantes.

Se recopiló un total de 107 mensajes de correos: 29 enviados por el profesor de Introducción al Estudio del Hombre; 64 por el de Práctica Profesional I y 14 por el de Psicología General y del Desarrollo. El cuarto profesor no hizo uso del correo electrónico durante el referido período. La investigación -por los procedimiento de triangulación- se extiende hasta marzo de 2016: con fines de realizar una triangulación metodológica y de datos (Denzin, 1989, cp. Flick, 2007), los resultados del análisis se envían por correo electrónico a los profesores para su revisión y emisión de comentarios. El análisis es devuelto por la misma vía. Los profesores de las tres

Andamiaje a la autorregulación académica a través del correo electrónico en un programa de formación docente de modalidad mista. Marcos Antonio Requena Arellano

Página 8 de 25 
materias validan el análisis: el profesor de Introducción al Estudio del Hombre lo hace no emitiendo ningún comentario sobre el mismo; y los profesores de Práctica Profesional I y de Psicología General y del Desarrollo lo hacen señalando su completo acuerdo con el mismo.

Debido a que la presentación del análisis se agrupa de acuerdo con el profesor remitente, y dado el poco espacio de este documento, los correos se citan sin otro dato de referencia. En los cuadros organizadores de los resultados, los códigos para señalar los andamios en las tablas y las figuras (como AC, EEBIRA, EIS, etcétera) son propuestos por el autor de la investigación solamente por razones de espacio y de facilitación de ubicación de cada andamio en el texto. En éste se presenta los códigos junto con el nombre al que cada uno hace referencia y su definición. Por otra parte, los tipos de andamios - de acuerdo con los tres criterios de clasificación obtenidos de la literatura- se señalan con los siguientes códigos:

- Adap (adaptabilidad): F (fijo), A (adaptativo).

- Fase: P (previsión), D (desempeño), R (reflexión).

- Proc (proceso): M (motivación), EM (establecimiento de metas), P (planificación), AM (automonitoreo), RP (regulación de procesos), Aev (autoevaluación), Aes (ajuste estratégico).

\section{Resultados y Discusión}

A continuación, se presentan los resultados del análisis de los correos electrónicos de las tres materias en las que se registra su emisión.

\section{En Introducción al Estudio del Hombre}

De esta materia se obtienen 29 correos enviados por el profesor, entre los que éste envía a todos los estudiantes y los que envía a estudiantes individuales. En los correos se identifican los siguientes doce andamios, los cuales son registrados en el Cuadro 2 de acuerdo con los tres criterios de la clasificación. Asimismo, se presentan organizados en la Figura 2 de acuerdo específicamente con el apoyo que ofrecen a los procesos de la autorregulación del aprendizaje; ello, con la finalidad de facilitar una visión comprehensiva de dicho aporte.

a) AC. Apoyo a la comprensión. Este andamio está referido a cualquier ayuda a la comprensión del contenido de la unidad temática tratada. Puede ofrecerse de manera fija o adaptativa, y contribuye con el automonitoreo y la regulación de procesos en la fase de desempeño. Se identifica en dos correos. En el ejemplo dado, el profesor, explica mediante la condición social del hombre la posibilidad de su actuación ética, y relaciona el contenido con el de otra materia

b) EEBIRA. Estimulación a estudiantes de baja involucración en actividades o con retraso en tareas. Se trata de un andamio que se provee solamente de manera adaptativa, orientado a favorecer la motivación en la fase de desempeño, por vía de la orientación al objetivo.

El EEBIRA se identifica en dos correos. En el ejemplo ofrecido, el profesor -mediante las negritas- hace una señalización indirecta de la condición evaluativa de los estudiantes, implicando un posible resultado indeseable en la evaluación de la materia

c) EIS. Estimulación al inicio de las sesiones. Este andamio, de tipo fijo, puede centrarse en varios resortes motivacionales: la autoeficacia, la valoración de la tarea,

Andamiaje a la autorregulación académica a través del correo electrónico en un programa de formación docente de modalidad mista. Marcos Antonio Requena Arellano

Página 9 de 25 
la orientación al objetivo o el ofrecimiento de recompensas, favoreciendo el control de la motivación en la fase de previsión.

Se identifica en tres correos. En el ejemplo, al inicio de la sesión 3, luego de señalar que en la misma se tiene planteada solamente la actividad de la lectura, la estimulación va dirigida a promover la valoración ésta.

d) ETE. Establecimiento de tiempos para entregas. Se trata de un andamio cuyo aprovechamiento puede darse para el establecimiento de metas y la planificación en la fase de previsión, así como para el automonitoreo en la fase de desempeño. Se observa en cuatro correos.

En el ejemplo, el profesor usa la mayúscula sostenida para enfatizar la importancia de la puntualidad de la entrega de la asignación.

e) IAR. Información sobre actividades a realizar. Se trata de un andamio fijo consistente en señalar las actividades planteadas en el plan de la sesión correspondiente, contribuyendo de manera indirecta con el establecimiento de metas en la fase de previsión.

Se identifica en diez correos. En el ejemplo dado, al inicio de la sesión 6, el profesor da la información contenida en el plan de la sesión y da precisiones respecto de lo esperado.

f) ICRE. Información y comentarios sobre resultados de evaluación. Este andamio adaptativo contribuye de manera indirecta con los dos procesos autorregulatorios de la fase reflexiva.

Durante el período objeto de análisis, se observa en un solo correo, enviado durante la sesión 3. En el referido correo, el profesor alerta a varios estudiantes sobre las implicaciones de no entregar un producto.

g) OA. Orientación sobre actividades. Este andamio -fijo o adaptativo- puede concretarse mediante una variedad de orientaciones: pautas, normas, procedimientos, estrategias o criterios de evaluación, todas contribuyentes con los el establecimiento de metas y la planificación en la fase de previsión y con el automonitoreo en la fase de desempeño.

Se observa en siete correos, todos durante el desarrollo de las actividades, contribuyendo particularmente con los procesos de la autorregulación durante la fase de desempeño. En el ejemplo dado, los aspectos que señala el profesor son los contemplados en el plan de la sesión 2.

h) Orientación técnica. Este andamio puede ser fijo o adaptativo, y está referido a cualquier orientación sobre el uso de las herramientas del aula virtual: su finalidad, ruta de acceso o procedimiento. Contribuye con la regulación de procesos en la fase de desempeño.

Se identifica en ocho correos. Buena parte de tales orientaciones son debidas a las fallas presentadas por el aula virtual del semestre durante las primeras sesiones del período. En el ejemplo ofrecido ofrece cargar en la nueva aula virtual las publicaciones para el foro que le envíen los estudiantes por correo. Asimismo, en el mismo correo, el profesor adjunta un documento en Word con las publicaciones realizadas por los estudiantes hasta ese día en el foro de discusión. 


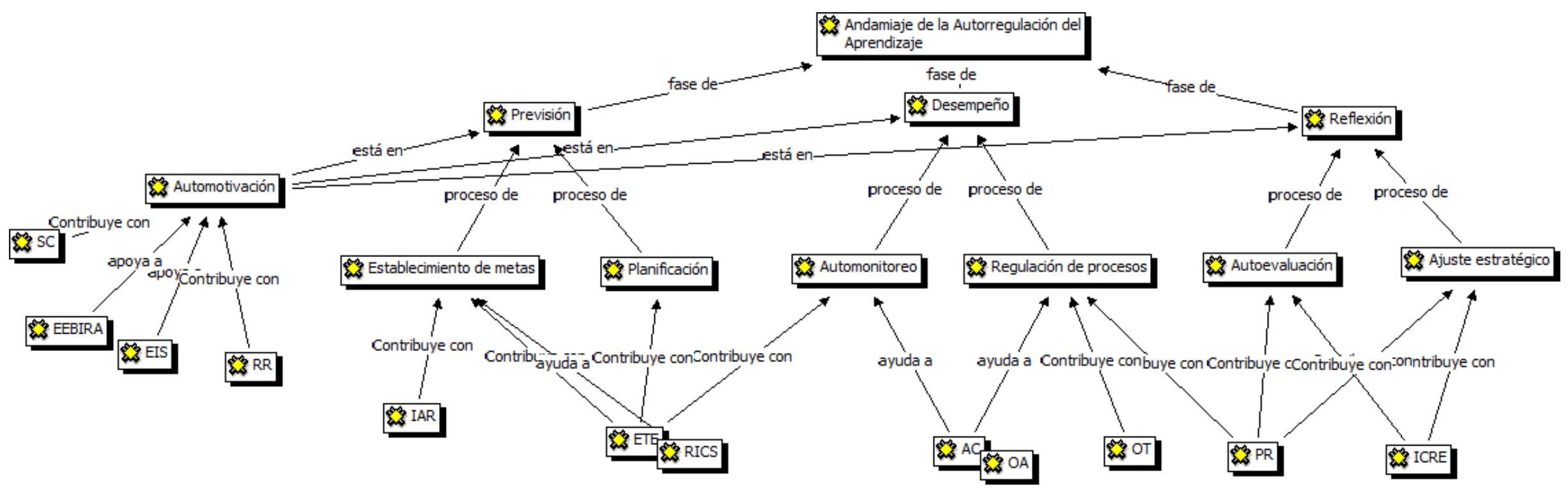

Figura 2. Andamios dados a la autorregulación del aprendizaje mediante correos de Introducción al Estudio del Hombre, de acuerdo con el proceso y la fase que se apoya. 
Cuadro 2. Andamios a la autorregulación del estudiante provistos en Introducción al Estudio del Hombre a través del correo electrónico. Adaptabilidad, fase y proceso que se apoya.

\begin{tabular}{|c|c|c|c|c|}
\hline Andamio & Adap & Fase & Proc & Ejemplo \\
\hline $\mathrm{SC}$ & $\mathrm{F}$ & Todas & M & Buenos días, estimados participantes \\
\hline EEBIRA & A & $\mathrm{D}$ & M & $\begin{array}{l}\text { [Remitiéndose a varios estudiantes]. Aún no he recibido ninguna de las asignaciones correspondientes a } \\
\text { Introducción al Estudio del hombre. Hasta ahora se han evaluado tres actividades sin respuesta de su } \\
\text { parte. }\end{array}$ \\
\hline EIS & $\mathrm{F}$ & $\mathrm{P}$ & M & $\begin{array}{l}\text { Para la sesión } 4 \text {, a partir del } 22 \text { de octubre, tendremos un foro en el que tendrán que demostrar el } \\
\text { dominio sobre dichas lecturas junto con algunas de las ideas que... }\end{array}$ \\
\hline ETE & $\mathrm{F}, \mathrm{A}$ & $\mathrm{P}, \mathrm{D}$ & $\mathrm{EM}, \mathrm{P}, \quad \mathrm{AM}$ & Al finalizar la sesión ustedes deberán haber 'colgado' en la plataforma... NO HABRÁ PRÓRROGA \\
\hline IAR & $\mathrm{F}, \mathrm{A}$ & $\mathrm{P}, \mathrm{D}$ & EM & $\begin{array}{l}\text { El día } 12 \text { de noviembre deberán presentar un informe escrito donde exponga los tópicos relativos a la } \\
\text { corporeidad, la esencia del ser humano y la autotrascendencia. No se esfuerce en una síntesis de los } \\
\text { textos; exponga de manera libre... }\end{array}$ \\
\hline RICS & $\mathrm{F}, \mathrm{A}$ & $\mathrm{P}, \mathrm{D}$ & EM, P, AM & A partir de hoy iniciamos la sesión 2 de Introducción al Estudio del Hombre. Al finalizar... \\
\hline $\mathrm{AC}$ & $\mathrm{F}, \mathrm{A}$ & $\mathrm{D}$ & AM, RP & $\begin{array}{l}\text { Todo ello, lo malo y lo bueno, es posible gracias a que el hombre es un ser social, tema que nos remite a } \\
\text { la asignatura Sociología de la Educación (sesión 8) }\end{array}$ \\
\hline $\mathrm{OA}$ & $\mathrm{F}, \mathrm{A}$ & $\mathrm{D}$ & AM, RP & $\begin{array}{l}\text { Por supuesto que ustedes pueden añadir otros textos para enriquecer su trabajo, siempre teniendo } \\
\text { cuidado de citarlos adecuadamente. Los aspectos solicitados son:... }\end{array}$ \\
\hline OT & $\mathrm{F}, \mathrm{A}$ & $\mathrm{D}$ & $\mathrm{RP}$ & $\begin{array}{l}\text { Para solventar la situación particular del FORO REFLEXIÓN ANTROPOLÓGICA [falla técnica del } \\
\text { foro en el aula virtual] los invito a mandar sus intervenciones a mi correo alterno... }\end{array}$ \\
\hline PR & $\mathrm{F}, \mathrm{A}$ & $\mathrm{D}, \mathrm{R}$ & RP, Aev, Aes & $\begin{array}{l}\text { Debemos plantearnos las preguntas que van al verdadero fondo de la excelencia docente: mi realidad } \\
\text { global como persona humana,... Se hace urgente una reflexión sobre... }\end{array}$ \\
\hline RR & A & $\mathrm{D}, \mathrm{R}$ & M & $\begin{array}{l}\text { He tenido una muy satisfactoria experiencia a lo largo de estas } 16 \text { semanas. Los animo a continuar en el } \\
\text { programa... }\end{array}$ \\
\hline ICRE & A & $\mathrm{R}$ & Aev, Aes & [El mapa] no ha si do colgado en la plataforma ni ha si do recibido por mí por el canal alterno habilitado \\
\hline
\end{tabular}


i) PR. Promoción de la reflexión. Este andamio -fijo a adaptativo-, contribuye de manera indirecta con la regulación de procesos en la fase de desempeño o los dos procesos de la fase reflexiva; ello, dependiendo del momento en que se provee.

Se observa en tres correos. En correo del ejemplo, a propósito del foro de discusión de la sesión 4, el profesor llama a los estudiantes a reflexionar sobre el papel de la universidad en su formación como seres integrales.

j) RICS. Recordatorio de inicio y cierre de la sesión. Este andamio -fijo a adaptativopuede contribuir con procesos de la fase de previsión o de la fase de desempeño de acuerdo con el momento en que se ofrece.

Se observa en siete correos. El ejemplo muestra el fragmento de un correo en el que el profesor precisa para ese día el inicio de la sesión 2.

k) RR. Retroalimentación reforzadora. Este andamio, de tipo adaptativo, promueve la motivación por la vía de la autoeficacia, pues fortalece en el estudiante la consideración sobre sí mismo como capaz ante los nuevos retos académicos. Dependiendo del momento de su provisión, favorece la motivación en las fases de desempeño o reflexión.

Se identifica en un solo correo. El fragmento mostrado indica que es enviado por el profesor al término del semestre. En el mismo, y en consecuencia de la retroalimentación dada, les anima a continuar con el Programa.

1) SC. Saludo cortés. Este andamio, por una ruta afectiva, contribuye con el establecimiento de un clima adecuado para la conformación o mantenimiento de la comunidad de aprendizaje. Al darse indistintamente del desempeño de los estudiantes, resulta un andamio fijo.

Se observa en la mayoría de los correos del profesor recolectados (sólo en dos no se presenta). El fragmento dado como ejemplo concreta el andamio de un modo formal y típico en el contexto académico.

\section{En Práctica Profesional I}

Se obtienen 64 correos enviados por el profesor, por la herramienta del aula virtual enviándolos a toda la sección- y por el correo Gmail personal -para envíos a estudiantes individuales.

En los correos se identifican los diez andamios registrados en el Cuadro 3, categorizados de acuerdo con los tres criterios establecidos. Asimismo, se presentan organizados en la Figura 3 de acuerdo específicamente con el apoyo que ofrecen a los procesos de la autorregulación del aprendizaje; ello, con la finalidad de facilitar una visión comprehensiva de dicho aporte.

a) AC. Apoyo a la comprensión. Se identifica en un solo correo, en el que tiene un estilo fijo. Se trata de un material sobre técnicas de recolección de datos, adicional a los materiales de lectura de la sesión.

b) DA. Declaración de disposición a la ayuda. Este andamio -fijo o adaptativo- favorece la motivación del estudiante, al contribuir con el establecimiento de un clima adecuado para la conformación o mantenimiento de la comunidad de aprendizaje.

Se registra en ocho correos. El fragmento dado como ejemplo es extraído de un correo a través del cual el profesor le da a un estudiante orientaciones sobre el planteamiento del problema de investigación, una de las asignaciones de la materia.

Andamiaje a la autorregulación académica a través del correo electrónico en un programa de formación docente de modalidad mista. Marcos Antonio Requena Arellano

Página 13 de 25 


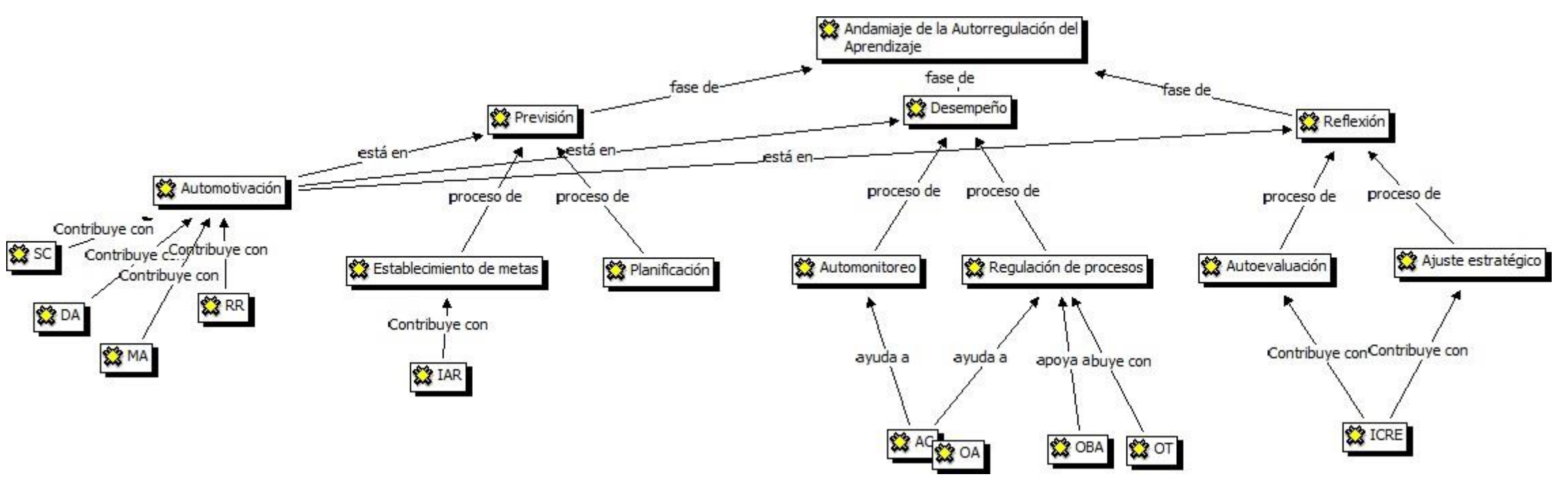

Figura 3. Andamios dados a la autorregulación del aprendizaje mediante correos de Práctica Profesional I, de acuerdo con el proceso y la fase que se apoya. 
Cuadro 3. Andamios a la autorregulación del estudiante provistos en Práctica Profesional I a través del correo electrónico. Adaptabilidad, fase y proceso que se apoya.

\begin{tabular}{|c|c|c|c|c|}
\hline Andamio & Adap & Fase & Proc & Ejemplo \\
\hline$\overline{\mathrm{SC}}$ & $\mathrm{F}$ & Todas & $\mathrm{M}$ & Buenos días, Ennio; Saludos cordiales \\
\hline DA & $\mathrm{F}, \mathrm{A}$ & $\mathrm{P}, \mathrm{D}, \mathrm{R}$ & M & Cualquier otra aclaratoria estoy a la orden. \\
\hline MA & A & $\mathrm{D}$ & M & Hola Astrid. Gracias por tu observación. Ya fue reportada dicha falla al CEL \\
\hline RR & A & $\mathrm{D}, \mathrm{R}$ & M & Buen trabajo José! \\
\hline IAR & $\mathrm{F}, \mathrm{A}$ & $\mathrm{P}$ & EM & $\begin{array}{l}\text { Mañana tendremos la actividad presencial. Para ello realizaremos un mapa conceptual donde se integren las } \\
\text { cuatro asignaturas trabajadas en este semestre. }\end{array}$ \\
\hline $\mathrm{AC}$ & $\mathrm{F}$ & $\mathrm{D}$ & $\mathrm{AM}, \mathrm{RP}$ & Estimad@s participantes. Les adjunto un material que les puede ser útil. \\
\hline OA & $\mathrm{F}, \mathrm{A}$ & $\mathrm{D}$ & AM, RP & $\begin{array}{l}\text { Hola Marisol. En tu caso lo que procede es contextualizar los distintos colegios de donde provienen esos } \\
\text { alumnos con los que trabajas. Haciendo... }\end{array}$ \\
\hline OBA & A & $\mathrm{D}$ & $\mathrm{RP}$ & $\begin{array}{l}\text { Hola Marisol. Acabo de chequear la plataforma y no veo tu trabajo del marco teórico. Cualquier duda o } \\
\text { inconveniente debes dirigirte a 'soporte de aula', o directamente al CEL. }\end{array}$ \\
\hline OT & $\mathrm{F}, \mathrm{A}$ & $\mathrm{D}$ & $\mathrm{RP}$ & $\begin{array}{l}\text { Debido a una falla en la plataforma, ya reportada al CEL, no pueden colgar la tarea de la sesión } 2 \text { (...). Por } \\
\text { tal razón, les recomiendo que ... }\end{array}$ \\
\hline ICRE & A & $\mathrm{R}$ & Aev, Aes & Ciertamente esta versión la veo mucho más aterrizada y factible. Mi única objeción es... \\
\hline
\end{tabular}


c) IAR. Información sobre actividades a realizar. Este andamio fijo se identifica en un solo correo, del cual se extrae el ejemplo ofrecido.

Es enviado durante la última semana de clase, en la víspera de la clase presencial; para ésta, los cuatro profesores tienen pautada una actividad integradora.

d) ICRE. Información y comentarios sobre resultados de evaluación.

Se observa en nueve correos, enviados a los estudiantes a propósito de los productos corregidos o de las calificaciones obtenidas en éstos.

e) MA. Manifestación de agradecimiento por alguna contribución. Este andamio también favorece la motivación del estudiante, al contribuir con el establecimiento de un clima adecuado en la comunidad de aprendizaje.

Se identifica en dos correos. El mensaje dado como ejemplo está referido a una emergente falla en el aula virtual, que impide a los estudiantes colgar en ella algún producto.

f) OA. Orientación sobre actividades. Al igual que en Introducción al Estudio del Hombre, este andamio se ofrece solamente durante la fase de desempeño, contribuyendo con el automonitoreo y la regulación de procesos.

Se observa en diez correos, en nueve de los cuales son de tipo adaptativo. El ejemplo dado corresponde a uno de estos casos, enviado en respuesta a la consulta vía correo de una participante respecto a las implicaciones de atender a una población estudiantil proveniente de distintos colegios (da clases particulares). En anotación hecha en documento con análisis para su validación, el profesor explica el uso del correo electrónico para atender consultas $-\mathrm{y}$ no del foro de dudas del aula virtual: "debido a la irregularidad del funcionamiento de la plataforma se tuvo que acudir al correo para aclarar dudas" (23-1-16)

g) OBA. Orientación sobre búsqueda de ayuda. Se provee en tres oportunidades: dos veces a la misma estudiante, y una vez a otro.

El ejemplo dado es un fragmento de un intercambio de correos entre la estudiante y el profesor, motivado por una falla técnica presentada por el aula virtual para fijar el producto que la estudiante intenta colgar.

h) OT. Orientación técnica. Se identifica en 16 correos, doce (12) de los cuales están motivados por las fallas presentadas por la plataforma las primeras seis sesiones. En los mismos se envía mensajes que hacen referencia a la misma situación que se muestra en el ejemplo dado.

En relación con ello, el profesor comenta al investigador, que durante el período se incrementó el intercambio de correos debido a la falla del aula virtual, que impedía a los estudiantes colgar sus productos. Los otros cuatro correos proveen este tipo de andamio por motivos del uso inadecuado de la plataforma por parte de algunos estudiantes.

i) RR. Retroalimentación reforzadora. Se observa en frases cortas como único mensaje de once correos, enviados algunos días posteriores a la recepción de algún producto.

El ejemplo dado es el mensaje de un correo enviado por el profesor a un estudiante a propósito de un mapa conceptual consignado el día anterior.

j) SC. Saludo cordial. Se observa en mayor o menor medida en todos los correos del profesor, tanto en los enviados a todo el grupo como a los remitidos a estudiantes en particular. Los ejemplos presentados corresponden a uno y otro caso. 


\section{En Psicología General y del Desarrollo}

De esta materia se obtuvieron 14 correos remitidos por la profesora a los estudiantes, todos enviados por el aula virtual, bien a toda la sección, bien a estudiantes de manera individual.

En los correos se identifican los siguientes seis andamios, los cuales son registrados en el Cuadro 4, clasificados según los tres criterios establecidos. Asimismo, se presentan organizados en la Figura 4 de acuerdo específicamente con el apoyo que ofrecen a los procesos de la autorregulación del aprendizaje; ello, con la finalidad de facilitar una visión comprehensiva de dicho aporte.

a) EEBIRA. Estimulación a estudiantes de baja involucración en actividades o con retraso en tareas.

Se observa en dos correos, en ambos casos enviando correo a todos los estudiantes a propósito de la baja participación en actividades colaborativas. El ejemplo dado corresponde a la Wiki que se realiza en la sesión 7.

b) IAR. Información sobre actividades a realizar.

Se identifica en un solo correo, el correspondiente al ejemplo dado. En este caso, el andamio apoya el establecimiento de metas en la fase de previsión.

c) ICRE. Información y comentarios sobre resultados de evaluación.

Se observa en dos correos enviados a todos los estudiantes y referidos a actividades colaborativas. El ejemplo dado se extrae de un correo enviado una semana después de la realización de la wiki, actividad de la sesión 7.

d) MADP. Manifestación adecuada de su dimensión personal. Este andamio es de tipo fijo, dado que es independiente del desempeño estudiantil. En Cualquier momento de la fase de autorregulación, contribuye con el establecimiento de un clima adecuado para la conformación o mantenimiento de la comunidad de aprendizaje. Se observa en dos correos.

El ejemplo dado se encuentra en un correo enviado por la profesora una semana antes de la última clase presencial, en la que se realizará una actividad integradora de las cuatro materias.

e) OA. Orientación sobre actividades.

Se observa en cuatro correos. A diferencia de Introducción al Estudio del Hombre y Práctica Profesional I, en esta materia se ofrece también (y principalmente) para la fase de previsión, contribuyendo con la planificación. El ejemplo dado es extraído de un correo enviado a propósito de la realización, en la sesión 2, de un cuadro comparativo de teorías de aprendizaje.

f) SC. Saludo cortés.

Se observa en mayor o menor medida en todos los correos de la profesora. El ejemplo dado es extraído de correo enviado el día antes del inicio de la sesión 2. 


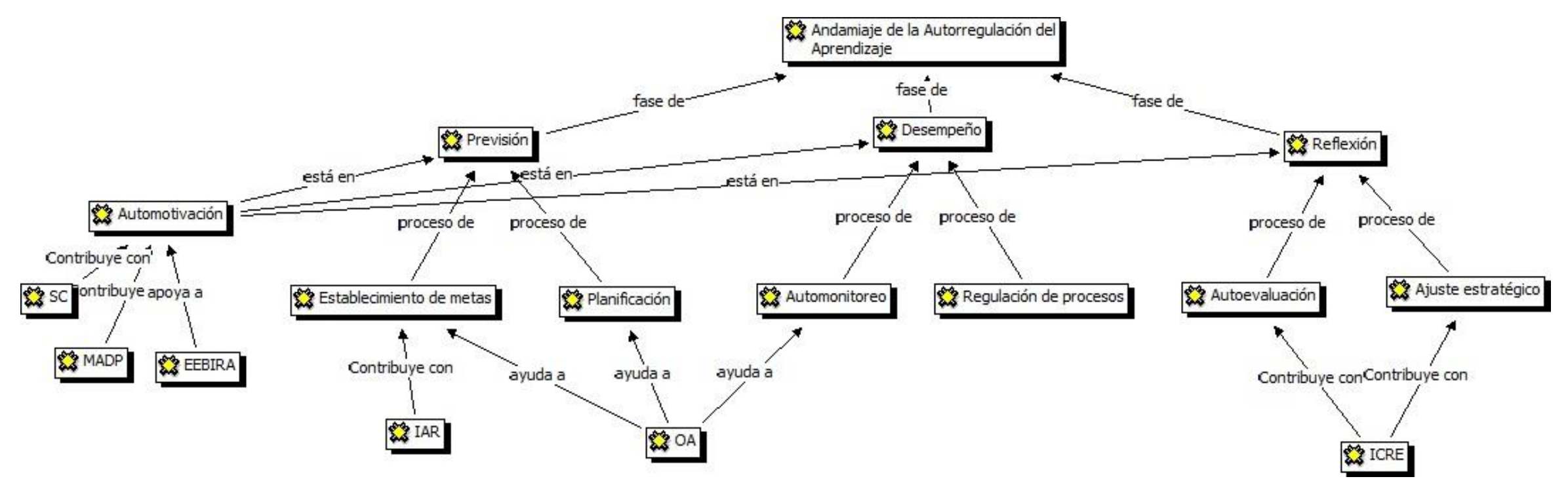

Figura 3. Andamios dados a la autorregulación del aprendizaje mediante correos de Psicología General y del Desarrollo, de acuerdo con el proceso y la fase que se apoya. 
Cuadro 4. Andamios a la autorregulación del estudiante provistos en Psicología General y del Desarrollo a través del correo electrónico. Adaptabilidad, fase y proceso que se apoya.

\begin{tabular}{|c|c|c|c|c|}
\hline Andamio & Adap. & Fase & Proc & Ejemplo \\
\hline$\overline{\mathrm{SC}}$ & $\mathrm{F}$ & Todas & $\mathrm{M}$ & $\begin{array}{l}\text { Buenas noches mis estimados estudiantes. Les } \\
\text { escribo para... }\end{array}$ \\
\hline MADP & F & Todas & M & $\begin{array}{l}\text { Este sábado } 7 \text { de febrero termino el Diplomado } \\
\text { de Coaching (...) para ese día debo presentar un } \\
\text { trabajo final y es la entrega de los diplomas en } \\
\text { horas de la mañana (...), les pido comprensión } \\
\text { por mi ausencia ese día. }\end{array}$ \\
\hline EEBIRA & A & D & M & $\begin{array}{l}\text { Veo con sorpresa que nadie ha participado, a } \\
\text { excepción de Pablo, pero me extraña mucho que } \\
\text { no ha participado nadie másiiii Qué pasa, están } \\
\text { inactivos o es el aula que está inactiva. }\end{array}$ \\
\hline IAR & $\mathrm{F}, \mathrm{A}$ & $\mathrm{P}$ & EM & $\begin{array}{l}\text { Dado que la última sesión, la \#16 tiene un foro } \\
\text { "Dejando Huellas" ustedes exponen sus } \\
\text { aprendizajes y sugerencias o comentarios con } \\
\text { respecto a esta asignatura. }\end{array}$ \\
\hline OA & $\mathrm{F}, \mathrm{A}$ & $\mathrm{P}, \mathrm{D}$ & $\mathrm{EM}, \mathrm{P}, \quad \mathrm{AM}$ & $\begin{array}{l}\text { Les escribo para proponerles realizar este } \\
\text { trabajo en parejas, Deben ponerse de acuerdo y } \\
\text { enviarme la respuesta por esta vía. Si lo van a } \\
\text { hacer en parejas... }\end{array}$ \\
\hline ICRE & A & $\mathrm{R}$ & Aev, Aes & $\begin{array}{l}\text { En términos generales sus intervenciones se } \\
\text { apegaron a lo establecido en una WIKI, es decir, } \\
\text { complementar una definición o una estrategia } \\
\text { entre todos, sin que esto se convierta en un Foro } \\
\text { de discusión. No es... }\end{array}$ \\
\hline
\end{tabular}

En síntesis, en las tres materias en la que se registran correos enviados por los profesores, se observa una variedad de andamios. Parte de los mismos constituyen respuestas a consultas hechas por los estudiantes; ello, aunque el aula virtual cuenta con un recurso especialmente destinado para ello: el foro de dudas.

En relación con el uso del correo electrónico para la provisión de andamios dados como respuestas a consultas hechas por estudiantes (véanse ejemplos de los andamios orientación sobre actividades y orientación técnica), se observó una disposición distinta entre los profesores: mientras que el de Introducción al Estudio del Hombre reconoce promocionarlo, los profesores de las otras dos materias declaran insistirles a los estudiantes presentar sus consultas por el foro de dudas (otra herramienta del aula virtual).

En relación con los tipos de andamios dados a la autorregulación del aprendizaje, en los correos de los profesores de las tres materias se identifican andamios fijos y adaptativos (Azevedo, Cromley, Moos, Grenne y Winters, 2011; Cho, 2012) en una proporción en la que prevalecen los primero. Apoyan procesos motivacionales y metacognitivos, distribuidos en las tres fases de la regulación académica: previsión, desempeño y reflexión (Zimmerman, 1989, 2013). Todos los andamios son de un estilo indirecto, dado que fomentan la autorregulación en el estudiante, pero no dan apoyo preciso sobre cómo realizar un proceso (Benz, 2010). 
Los andamios identificados corresponden con categorías establecidas por el investigador -como un paso del análisis de contenido- a partir de lo expuesto por Hodges y Kim (2010), Inglis (1998), Kim (2008), Lee (2001), Monforte (2003), (Pastor Cesteros, 1999), Puerta y Sánchez (2010) y Spence (2002).

Se encuentra una notable desigualdad cuantitativa en la provisión de andamios por parte de los tres profesores: 12 andamios en los 29 correos consignados por el profesor de Introducción al Estudio del Hombre; 10 en los 64 correos entregados por el profesor de Práctica Profesional I; y 6 en los 14 correos enviados por la profesora de Psicología General y del Desarrollo. Tómese en cuenta en este punto el hecho de que el profesor de Sociología de la Educación declaró haber enviado a los estudiantes 2 o 3 correos durante el período, los cuales no pudo facilitar a investigador por haberlos eliminado.

La tipología de los andamios también presenta diferencias proporcionales (Gráfico 1).

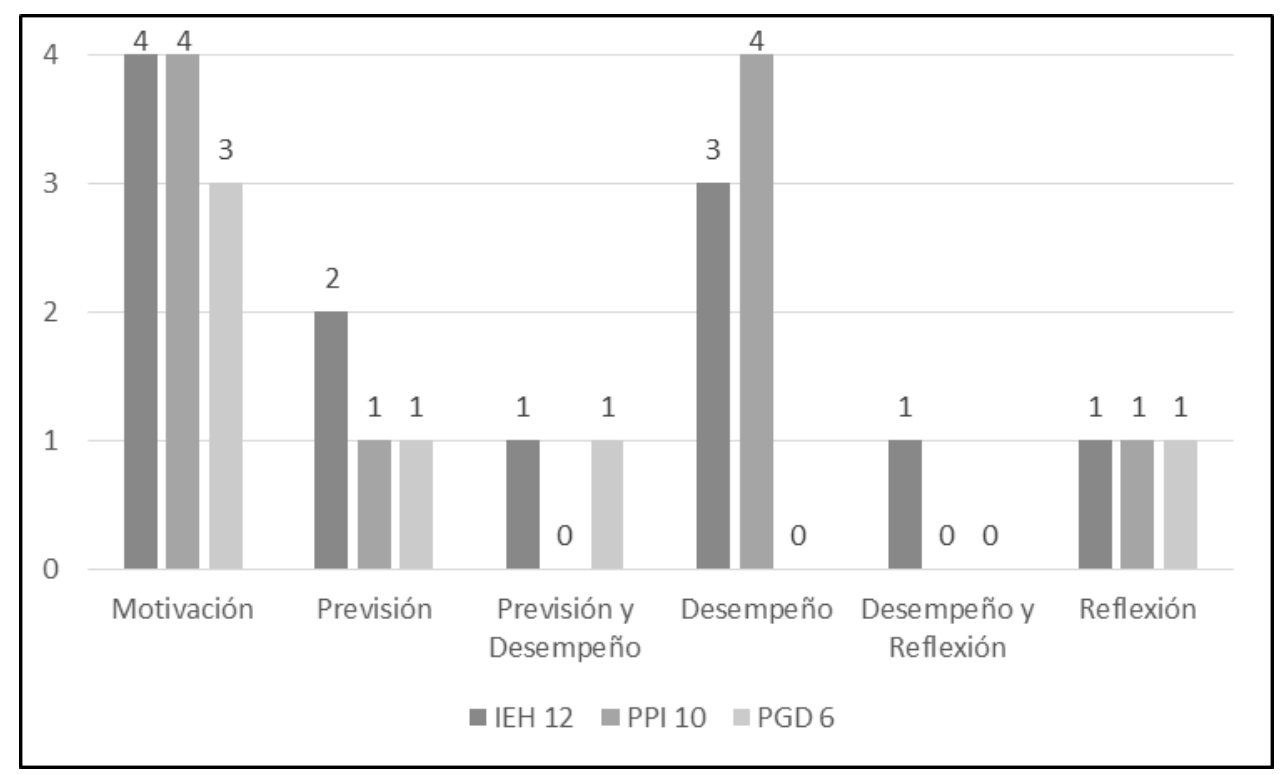

Gráfico 1. Fase del aprendizaje autorregulado a la que se provee andamiaje mediante el correo electrónico en tres de las cuatro materias del Primer Semestre del PRESLIED.

De los 12 andamios ofrecidos por el profesor de Introducción al Estudio del Hombre, 4 (34\%) apoyan procesos motivacionales, 2 (17\%) apoya procesos de la fase de previsión, $1(8 \%)$ apoyan procesos tanto de la fase de previsión como de desempeño, $3(25 \%)$ apoya procesos de la fase de desempeño, 1 (8\%) de las fases de desempeño y reflexión y $1(8 \%)$ de la fase de reflexión. En Práctica Profesional I, de los 10 andamios identificados, a (40\%) favorecen procesos motivacionales, $1(10 \%)$ favorece procesos de la fase de previsión, $4(40 \%)$ de la fase de desempeño y $1(10 \%)$ de la fase de reflexión. En Psicología General y del Desarrollo, de los 6 andamios observados, 3 $(50 \%)$ apoyan procesos motivacionales, $1(17 \%)$ procesos de la fase de previsión, 1 $(17 \%)$ procesos de la fase de previsión y desempeño y $1(17 \%)$ procesos de la fase de reflexión.

Estas proporciones permiten sostener que, en relación con el tipo de andamio, y con excepción al tipo referido al estilo, en los correos de los tres profesores se observa una desigual distribución. En relación con los andamios favorecedores del control de la motivación, se observa que prevalecen en las tres materias. Los tres profesores comparten la provisión de saludos cordiales (SC), los cuales favorecen la motivación por la vía del establecimiento de un clima favorable en la comunidad de aprendizaje.

Andamiaje a la autorregulación académica a través del correo electrónico en un programa de formación docente de modalidad mista. Marcos Antonio Requena Arellano

Página 20 de 25 
Adicionalmente, los tres profesores proveen, cada uno, otros andamios que favorece la motivación; en este caso, contribuyendo con el clima de la comunidad (como la disposición a la ayuda) o por vía de la orientación al objetivo (como la estimulación al inicio de sesiones) o la valoración de la tarea (como la estimulación a estudiantes con baja involucración en actividades o con retraso en tareas). No se identifican andamios favorecedores de la autoeficacia.

Respecto de los andamios a procesos metacognitivos de las tres fases del ciclo de autorregulación, las proporciones antes señaladas dejan ver que en Introducción al Estudio del Hombre y Práctica Profesional I principalmente se apoyan los procesos de la fase de desempeño (el automonitoreo y la regulación de procesos), en segundo lugar los de la fase de previsión (el establecimiento de metas y la planificación) y finalmente, de manera marginal, los de la fase de reflexión (la autoevaluación y el ajuste de procesos). Por su parte, en Psicología General y del Desarrollo, los procesos metacognitivos de las tres fases son apoyados de una manera similarmente marginal.

Por otra parte, en el período tiene lugar una situación atípica, que modifica en parte el uso del correo electrónico: la falla del aula virtual durante las primeras seis semanas, consistente en imposibilidad de que los estudiantes envíen sus trabajos por la plataforma, borrado inexplicable de publicaciones en los foros de discusión o impedimento de entrar a esta actividad. Esto generó dos usos adicionales para el correo electrónico: a) el envío de trabajos al profesor y b) consultas cuyos temas son de interés a todo el curso, por lo que deben hacerse por el foro de dudas.

\section{Conclusiones}

Lo anterior permite generar algunas conclusiones respecto del andamiaje dado mediante el correo electrónico a la autorregulación académica de los estudiantes del programa universitario objeto de estudio. Las mismas, con relevancia para próximas investigaciones, son:

a) El correo electrónico es un recurso TIC aprovechable para la provisión de andamios a la autorregulación académica. Mediante tal herramienta TIC, puede proveerse a las estudiantes andamios para su autorregulación académica, pertenecientes a los distintos tipos contemplados por las tipologías consideradas en la presente investigación.

b) En la identificación de los distintos tipos de andamios, se destaca como un resultado emergente de particulares implicaciones teóricas y prácticas la integración de los nueve andamios que apoyan procesos motivacionales: cinco andamios (EIS, DA, MA, MADP y SC) que promueven la afectividad y el clima social (Gárrison y Anderson, 2005; Sánchez-Upegui, 2009); dos (EIS y RR) que contribuyen con la autoeficacia (Cho, 2012); y dos (EEBIRA y EIS) que promueven la orientación al objetivo y la valoración de la tarea (Efklides, 2009; Pintrich, 2004). Estos andamios están asociados con variados enfoques sobre la motivación. En tal sentido, desde el punto de vista teórico, esta integración de andamios motivacionales implica la existencia de una relación de complementariedad entre las diversas teorías que explican la motivación por el aprendizaje en contextos académicos. Por otra parte, desde un punto de vista práctico, implica la pertinencia y conveniencia de que el docente ofrezca ayuda a la motivación de los estudiantes haciendo uso de estrategias que activan variados factores.

Andamiaje a la autorregulación académica a través del correo electrónico en un programa de formación docente de modalidad mista. Marcos Antonio Requena Arellano

Página 21 de 25 
c) El aprovechamiento del correo electrónico, en el contexto y período estudiados, difiere considerablemente en lo que respecta a los procesos autorregulatorios apoyados: unos procesos fueron notablemente más apoyados que otros. En tal sentido, se ha encontrado un notable desequilibrio en el andamiaje brindado a la autorregulación. Si se toma en cuenta que las tres fases del ciclo de la autorregulación son necesarios para el logro progresivo de nuevos niveles de aprendizaje y de estrategias para regularlo, se concluye que desde la práctica docente debe brindarse a los estudiantes un apoyo equilibrado a las tres fases de la autorregulación.

d) La fase de la autorregulación que recibió un menor número de andamios es la correspondiente a los procesos reflexivos. Esto, a nuestro parecer, representa una importante deficiencia: los procesos de la fase reflexiva son los que permiten que el estudiante, respecto de su autorregulación, obtenga aprendizajes valiosos para transferir a nuevas experiencias; sin dichos aprendizajes, tenderá a repetir las mismas estrategias y del mismo modo.

e) Respecto del tipo de andamio respecto a la adaptabilidad, resulta conveniente dar mayor espacio al andamiaje adaptativo, esto es, al provisto al estudiante de acuerdo con su necesidad o desempeño. La prominencia de andamios fijos implica una centración de la atención en necesidades del grupo, con descuido de necesidades individuales.

f) Otra diferencia notable se observó entre los profesores, respecto de la variedad de tipos de andamios ofrecidos. Dado que en una actividad educativa dada en entorno digital interactúan factores del estudiante, del contenido, del docente y del contexto técnico-ambiental (Requena, 2015), esta diferencia puede ser debida a una conjunción de los siguientes aspectos: a) del docente: disposición para proveer apoyo al estudiante en su autorregulación; formación respecto de la autorregulación y su andamiaje; familiaridad en el uso educativo del correo electrónico; b) del estudiante: diferencias grupales e individuales en la necesidad de apoyo a su autorregulación, para atender las demandas de las tareas en cada materia; c) del contenido: diferencias de demandas al estudiante, que generan diferencias en las necesidades de autorregulación; del entorno técnico-ambiental: presencia de otras herramientas comunicacionales del aula (como el foro de dudas) aprovechables para la provisión de andamios.

Con base en lo anterior, el investigador permite recomendar:

a) Incorporar el uso del correo electrónico a la práctica comunicacional del docente universitario, con fines de proveer andamios a la autorregulación académica de los estudiantes. Independientemente de la modalidad de la carrera o del programa, el correo electrónico es un recurso TIC de amplio y fácil acceso: gracias a la tecnología móvil, para su uso no se requiere de una computadora. Basta que el dispositivo tenga servicio de datos.

b) Orientar esta incorporación mediante la formación del docente, con fines de que éste haga un uso eficaz del correo electrónico en el andamiaje de la autorregulación académica de los estudiantes.

c) Realizar investigaciones que permitan contrastar y posiblemente validar las conclusiones derivadas de esta investigación. Las anteriores conclusiones tienen validez en el contexto en que fue realizada la investigación. Posteriores investigaciones, ejecutadas en otros contextos, podrían dar aportes para su

Andamiaje a la autorregulación académica a través del correo electrónico en un programa de formación docente de modalidad mista. Marcos Antonio Requena Arellano

Página 22 de 25 
contrastación y eventual generalización. Dado que el correo electrónico es en la actualidad una de las herramientas TIC de mayor uso por parte de la población con acceso a la Internet, aunque la investigación que acá se reporta está referida a un programa de modalidad mixta con énfasis en actividades a distancia, la investigación sobre el aprovechamiento de la referida herramienta para apoyar la autorregulación de los estudiantes podría tener lugar también en programas presenciales.

Presentación del artículo en versión original: 29 de abril de 2016

Fecha de aprobación: 19 de octubre de 2016

Fecha de publicación: 15 de noviembre de 2016

Requena, M. (2016). Andamiaje a la autorregulación académica a través del correo electrónico en un programa de formación docente de modalidad mixta. RED. Revista de Educación a Distancia. 51(7). Consultado el (dd/mm/aaaa) en http://www.um.es/ead/red/51

\section{Referencias}

Azevedo, R., A. Jeffrey, A. Greene \& D. Moos. (2007). The effect of a human agent's external regulation upon college students' hypermedia learning. Metacognition \& Learning 2, 67-87. doi: 10.1007/s11409-007-9014-9

Azevedo, R., J. Cromley, D. Moos, J. Greene \& F. Winters (2011). Adaptive Content and Process Scaffolding: A key to facilitating students' self-regulated learning with hypermedia. Psychological Test and Assessment Modeling,53(1), pp.106-140. Disponible en: https://www.researchgate.net/profile/Jeffrey_Greene/ publications

Bandura, A. (1977). Social Learning Theory. Engleegood Cliff: Prentice-Hall.

Benz, B. (2010). Improving the Quality of E-Learning by Enhancing Self-Regulated Learning. A Synthesis of Research on Self-Regulated Learning and an Implementation of a Scaffolding Concept. Darmstadt: Technische Universität Darmstadt: Tesis doctoral no publicada. Disponible en: http://tuprints.ulb.tudarmstadt.de/2194/1/Dissertation_Benz.pdf

Boekaerts, M. (1999). Self-regulated Learning: where we are today. International Journal of Educational Research, 31, 445-457. Disponible en http://www.sciencedirect.com/ science/article/pii/S0883035599000142

Cáceres, P. (2003). Análisis cualitativo de contenido: una alternativa metodológica alcanzable. Psicoperspectivas, 2, 53-82. Disponible en: http://www. psicoperspectivas.cl/index.php/sicoperspectivas/\%20article/viewFile/3/3

Cho, M. (2012). Online student orientation in higher education: a developmental study. Education Teach Research Dev, 60, 1051-1069. doi: 10.1007/s11423-012-9271-4

Devolder, J. Van Braak \& J. Tondeur (2012). Supporting self-regulated learning in computer-based learning environments: systematic review of effects of scaffolding in the domain of science education. Journal of Computer Assisted Learning, 28, 557-573. doi: 10.1111/j.1365-2729.2011.00476.x

Efklides, A. (2009). The role of metacognitive experiences in the learning process.

Andamiaje a la autorregulación académica a través del correo electrónico en un programa de formación docente de modalidad mista. Marcos Antonio Requena Arellano

Página 23 de 25 
Psicothema, 21(1), 76-82. Disponible en http://www.unioviedo.es/reunido/ index.php/PST/article/view/8799/8663

Flick, U. (2007). Introducción a la investigación cualitativa. Madrid: Morata. Garrison, D. \& Anderson, T. (2005). El e-learning en el siglo XXI. Investigación y práctica. Barcelona: Octaedro.

Gárrison, D. \& Anderson, T. (2005). El e-learning en el siglo XXI. Investigación y práctica. Barcelona: Octaedro.

Hernández, S. (2008). El modelo constructivista con las nuevas tecnologías: aplicado en el proceso de aprendizaje. Revista de Universidad y Sociedad del Conocimiento, 5(2), 26-35. Disponible en http://dialnet.unirioja.es/servlet/articulo?codigo=2799725

Hodges, Ch. \& Kim, Ch. (2010). Email, self-regulation, self.efficacy, and achievement in a college online mathematics course. Journal of Educational Computing Research, 43(2), 207-223. doi: 10.2190/EC.43.2.d

Inglis, A. (1998). Video email: a method of speeding up assignment feedback for visual arts subjects in distance education. British Journal of Educational Technology, 29(4), 343-354. Rescatado de la base de datos Ebsco Host.

Kim, Ch. (2008). Using email to enable $\mathrm{e}^{3}$ (effective, efficient, and engaging) learning. Distance Education, 29(2), 187-198. doi: 10.1080/01587910802154988

Lee, K. (2001). Using Telecollaboration for Self-regulated Thinking Skills: instruction with regular and gifted learners. High Ability Studies, 12(2), 235-247. doi: $10.1080 / 13598130120084357$

Monforte, C. (2003). Cómo optimizar la educación abierta y a distancia con tecnologías horizontales, el email. RED: Revista de Educación a Distancia, 8, 1-7. Disponible en: https://dialnet.unirioja.es/ejemplar/116340

Pastor-Cesteros, S. (1999) "Nuevas perspectivas para el desarrollo de la expresión escrita: El intercambio de correo electrónico" Carabela, septiembre, 119-136. Disponible en: http://rua.ua.es/dspace/handle/10045/48772

Pintrich, P. (2004). A conceptual framework for assessing motivation and self-regulated learning in college students. Educational Psychology Review, 16(4), 385-407. doi:10.1007/s10648-004-0006-X

Puerta, C. y A. Sánchez (2010). El correo electrónico: herramienta que favorece la interacción en ambientes educativos virtuales. Revista Virtual Universidad Católica del Norte, 30, 1-27. Disponible en: http://www.redalyc.org/pdf/ 1942/194214476003.pdf

Requena, M. (2015). Aportes para la construcción de un modelo conceptual para el diseño, evaluación e investigación en educación virtual. Archivos de Ciencias de la Educación, 9(9), 1-9. Disponible en: http://www.archivosdeciencias. fahce.unlp.edu.ar/article/view/Archivos09a08

Sánchez-Upegui, A. (2009). Nuevos modos de interacción educativa: análisis lingüístico de un foro virtual. (Spanish). Educación Y Educadores, 12(2), 29-46.

Andamiaje a la autorregulación académica a través del correo electrónico en un programa de formación docente de modalidad mista. Marcos Antonio Requena Arellano 
Spence, L. (2002). Like building a new motorway': establishing the rules for ethical email use at a UK Higher Education Institution. Business Ethics: A European Review, 11(1), 40-51. Rescatado de la base de datos de Ebsco Host.

Winne, P. (2005). A perspective on state-of-the-art research on self-regulated learning. Instructional Science, (33), 559-565. doi: 10.1007/s11251-005-1280-9

Zimmerman, B. (1989). A Social Cognitive View of Self-Regulated Academic Learning. Journal of Educational Psychology, $81 \quad$ (3), 329-339. doi:10.1037/0022-0663.81.3.329

Zimmerman, B. (2008) Investigating Self-Regulation and Motivation: Historical background, Methodological Developments and Future prospects. American Educational Research Journal, 45, (1), 166-183. Disponible en: http://aer.sagepub.com/content/45/1/166.short

Zimmerman, B. J. (2013). From Cognitive Modeling to Self-Regulation: A Social Cognitive Career Path. Educational Psychologist, 48(3), 135-147. doi:10.1080/00461520. 2013.794676 